\section{Reforma universitaria y extensión, marcas en el pensamiento universitario de José Luis Romero}

Eduardo A. Escudero

Universidad Nacional de Río Cuarto.

Universidad Nacional de Córdoba,

Argentina.

escuderoea@yahoo.com.ar
A 100 años de la Reforma Universitaria de 1918 /

Perspectivas

RECEPCIÓN: 29/06/17

ACEPTACIÓN FINAL: 24/08/17

\section{Resumen}

Esta intervención se funda en el rescate y la lectura de algunos ángulos relevantes del pensamiento universitario de José Luis Romero (1909-1977), historiador e intelectual argentino de notable protagonismo en la vida universitaria, fundamentalmente entre 1955 y 1965 . En ese sentido, se consideran sus ideas acerca del reformismo en general y de la extensión universitaria en particular, se observan los aspectos de un pensamiento epocal, formalizado en un tiempo que claramente ya no es este, pero que, sin dudas, transmuta los distintos clisés y etapas de una tradición progresista y proyectiva en la cultura y la política argentina y latinoamericana. Para tal fin se acude a algunos pasajes fundamentales de textos claves en los que el historiador e intelectual argentino plasmó los nudos de su representación crítica acerca de la universidad argentina y latinoamericana.

\section{Resumo}

Esta participação se baseia no resgate e leitura de alguns aspectos relevantes do pensamento universitário de José Luis Romero (1909-1977), historiador e intelectual argentino de notado protagonismo na vida universitária, principalmente entre 1955 e 1965. Nesse sentido, consideram-se suas ideias acerca do reformismo em geral, e da Extensão universitária em particular, observando os sentidos de um pensamento da época, formalizado em um tempo que, com certeza não é o atual, mas, sem dúvidas, transmuta os diferentes clichês e etapas de uma tradição progressista e projetista na cultura e política da Argentina e da América Latina. Para isto, vale-se de alguns trechos fundamentais de textos elementares onde o historiador e intelectual argentino desvelou os eixos de sua representação crítica acerca da universidade argentina e na América Latina.
Palabras clave

- Reforma universitaria

- Extensión

- Pensamiento universitario

- José Luis Romero
Palavras-chave

- Reforma Universitária

- Extensão

- Pensamento universitário

- José Luis Romero
Para citación de este artículo

Escudero, E. A. (2017). Reforma universitaria y extensión, marcas en el pensamiento universitario de José Luis Romero. Revista $+E$ versión en línea, 7(7), 38-45. Santa Fe, Argentina: Ediciones UNL. 


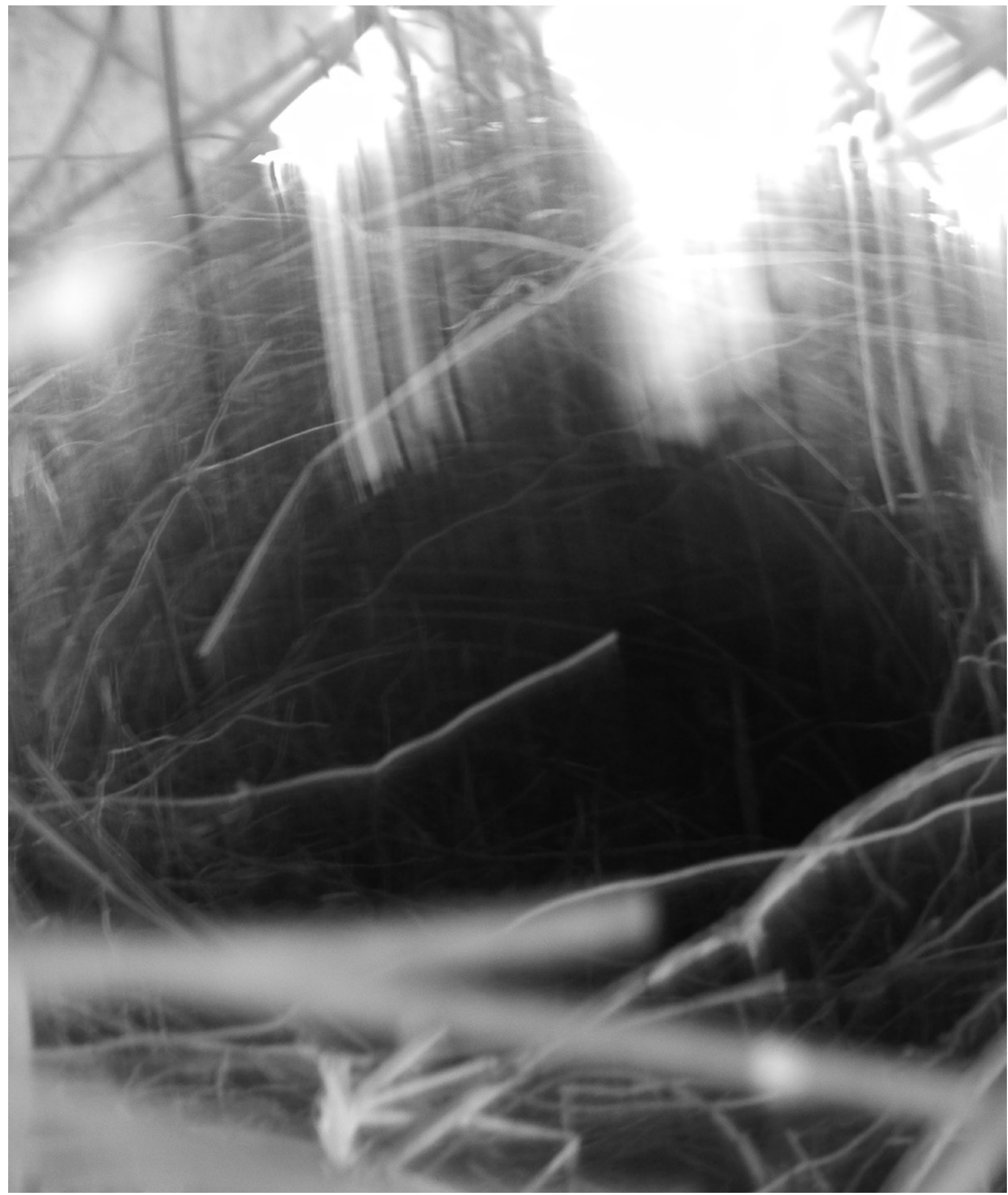

() Cecilia lucci 


\section{Introducción}

"Se consideró necesario salir al encuentro de los problemas nuevos, formularlos en términos precisos, afrontarlos decididamente y, abandonando prejuicios, convenciones e intereses creados, ofrecer soluciones que no rehuían parecer, en alguna medida, revolucionarias."

José Luis Romero, 1978.

A lo largo del intenso siglo XX, la universidad como constructo histórico fue objeto de distintas discusiones y controvertidas enunciaciones. En efecto, en tanto caja de resonancia de los múltiples procesos sociales, ese espacio destinado a la consagración de saberes y a la edificación de nuevas matrices de conocimiento e interpretación del mundo involucró un dialéctico comportamiento entre temporalidades en conflicto: entre lo nuevo y lo viejo, entre lo transparente y lo opaco, entre la tradición y la modernidad, entre la democracia y la oligarquía. En esas relaciones binarias, ejemplos de una representación del mundo proclive a la Modernidad, la universidad a menudo se vio sospechada de clásica o transformadora, acusada a veces de responder a modelos excluyentes o de acercar nuevas propuestas de cambio histórico y animar la consecución de horizontes utópicos.

En ese sentido, como es sabido, la aurora del siglo en Latinoamérica se vio interpelada por distintas experiencias de crítica cultural y ruptura política. La Reforma universitaria de 1918 en Córdoba fue, entre estas, una de las más potentes por su novedosa enunciación de los males que aquejaban no solo a la universidad y a los universitarios, sino también a las sociedades que los contienen, a la vida histórica que los subsume en crisis y, como correlato, a los valores que los alcanzan. No es aquí el lugar de avanzar sobre las complejas inteligencias y sensibilidades de coyuntura que nutrieron de manera cabal al experimento reformista de 1918, para ello existen, por fortuna, numerosos estudios que indagan acerca de las matrices filosóficas y políticas de un fenómeno, sin dudas, muy matizado (Portantiero, 1978; Halperin Donghi, 2005; Tünnermann Bernheim, 2008; Buchbinder, 2008; Finocchiaro, 2013). Sí, en cambio, es preciso considerar el modo en que las sucesivas capas de lecturas acerca de la Reforma, desde las contemporáneas hasta las del más cercano presente, sin dudas acusan la performatividad de una tradición (Hobsbawm y Ranger, 1983). En efecto, el reformismo ${ }^{1}$ puede considerarse una tradición inventada que ha establecido o simbolizado,

1) A pesar de su luminosidad $y$ de su inercia, incluso, internacional, la tradición reformista fue un proyecto truncado, dadas las específicas condiciones del proceso político y cultural argentino. Con todo, la Reforma reclamaba una universidad abierta al mundo, a Latinoamérica, pero no dejaba de ser pensada en términos de espacio de virtud, de una aristocracia cultural que, en buena medida, encarnaba a la vanguardia del saber en senda liberal. Mencionamos sólo dos de los muy importantes puntos que caracterizan a la tradición reformista, puntos que creo habilitan la discusión hasta el presente.

hasta la actualidad, un dispositivo/discurso de cohesión social o pertenencia a una tendencia política, reproduciendo una creencia acerca de lo que positivamente se supone debe habitar y ser experimentado en la universidad. Así, lejos de ser una imagen inmóvil, la de la Reforma universitaria fue y es una dúctil representación que, en el espejo de la política, ha ofrecido, y aún lo hace, interesantes e interesadas apropiaciones.

En el transcurrir de la historia de la cultura, las ideas y la universidad argentina y latinoamericana, la figura de José Luis Romero (1909-1977) adquiere singulares dimensiones (Halperin Donghi, 1980 y Acha, 2005). Historiador peculiar, distante de las tradiciones liberales y nacionalistas que vertebraron el sentido común histórico del país desde principios del siglo XX y principal puntos de referencia para la renovación de la historiografía y demás ciencias sociales desde 1955, su intelectualidad pudo conmover los cánones desde los que se imaginaban las instituciones y sus proyecciones. Entre estas, la universidad obtuvo, en el marco de sus múltiples y valiosas intervenciones intelectuales, un lugar destacado, en tanto el autor encarnó un tipo especial de perfil académico, aquel no subsumido totalmente en las artes de las humanidades, sino también decididamente presto a reflexionar sobre el mundo que transcurría y, en ese continuo cultural, al propio país en perspectiva cosmopolita. Este "argentino universal", como alguna vez lo llamó el historiador Alberto Ciria (1934-2005), se desplazó sinuosamente desde los márgenes a la centralidad del campo historiográfico (Haperin Donghi, 1980) y de las recientemente renovadas ciencias sociales en la Argentina. Así, alcanzó el rango de historiador internacionalmente consagrado merced a sus aportes, fundamentalmente, sobre historia medieval y de las ciudades latinoamericanas, y tuvo una importante participación en la vida universitaria del país, especialmente en la controvertida etapa institucional y política abierta luego del golpe de Estado de 1955 (Buchbinder, 2005).

Aunque sin dudas signado por la dictadura y la proscripción y persecución del peronismo, el tiempo que viabilizaba la segunda mitad de la década del '50 y los años 60 lo encontrará primero como rector de la Universidad de Buenos Aires y, luego, en 1962, como decano de la Facultad de Filosofía y Letras de la misma Casa (Acha, 2005). En ese contexto fecundo, interpelado por los debates acerca del futuro mismo de la universidad, Romero fervorosamente buscó hacer efectivos los postulados y valores

Uno de ellos remite a la democratización efectiva en tanto apertura de la universidad a otros sectores sociales. Luego, el segundo, de carácter más filosófico, ideológico y epistémico, vinculado al tipo de saberes producidos, enseñados y comunicados en y desde las universidades públicas: a saber, si se los concibe desde el liberalismo universalista de corte ilustrado o sí, en cambio, se los expone desde las matrices de la imaginación nacionalista, regional, erigidos en y desde las identificaciones y necesidades propias de nuestras sociedades periféricas, dependientes. 
del reformismo y alcanzar un ideal universitario atento, según él mismo precisaba, al intenso proceso de crisis en la cultura. De matriz socialista, el progresismo del intelectual articulaba una viva preocupación por hacer de la universidad una experiencia eminentemente democrática, cerrada tal vez a la articulación política de sus actores y a la sensibilidad del saber abierto a la crítica social. Este horizonte, sin embargo, pronto no encontraría una solución posible cuándo, en la década de la contestación y de la radicalización política que sigue al golpe de Estado de 1966 y luego al Cordobazo, otros actores imaginaran una universidad más tajantemente disolvente de las estructuras del mundo capitalista desde la periferia.

Seguidamente, se considerarán algunas de las ideas de José Luis Romero acerca de la Reforma universitaria en general y de la extensión universitaria en particular. Se trata de algunos de los relieves de un pensamiento epocal, formalizado en un tiempo que claramente ya no es este pero que, sin dudas, transmuta los distintos clisés y etapas de una tradición progresista, proyectiva, aunque también condicionada por un determinado prisma en torno al pensamiento universitario. Para tal fin se recurre a algunos pasajes fundamentales de textos claves en los que el historiador e intelectual argentino plasmó los nudos de su representación crítica acerca de la universidad argentina y latinoamericana.

\section{Los espejos de la Reforma universitaria en clave romeriana} En un ensayo publicado póstumamente, José Luis Romero plasmó de modo más complejo y completo que en anteriores mediaciones su visión historiográfica de la Reforma universitaria de 1918. A su juicio, esta se había desencadenado como reacción contra "la inmovilidad y el anacronismo" de las universidades y había asumido como objetivo general su renovación y modernización. Sin embargo, él mismo advertía que las mencionadas renovación y modernización debían ir "más allá de sus simples contenidos pedagógicos". Al respecto puntualizaba:

"La Reforma pretendió no solo que la universidad actualizara el contenido y los métodos de la enseñanza sino también que modificara constantemente su concepción del papel que debía desempeñar en la sociedad, teniendo en cuenta los cambios que en ésta se habían producido y las tendencias que en ella se manifestaban. (...) En todo caso, la idea de una universidad estática, concebida corno una academia en la que el saber simplemente se conservaba y se trasmitía, pareció inadecuada para la dramática época que siguió a la Primera Guerra Mundial: Se consideró necesario salir al encuentro de los problemas nuevos, formularlos en términos precisos, afrontarlos decididamente $y$, abandonando prejuicios, convenciones e intereses creados, ofrecer soluciones que no rehuían parecer, en alguna medida, revolucionarias". (1978:185)
En esa escritura prima la precisión de un ideal reformista que proponía un determinado "dinamismo" a la universidad, una inestabilidad que, de acuerdo con lo asegurado por el historiador, se enfrentaba tanto contra los intereses de las clases dominantes como con el sistema institucional del que las universidades formaban parte. Esto, precisamente, posibilitaría, según Romero, comprender, por ejemplo, el énfasis puesto sobre la bandera de la autonomía universitaria.

Partiendo de esta representación, el historiador socialista, portador de un idealismo filosófico de corte progresista, hacia mediados del siglo XX hacía suya la imagen de la Reforma universitaria y la consideraba un jalón en la consecución de una auténtica democracia en la que "el pueblo" se compenetrara con el proyecto a punto de hacer de este un baluarte y resguardo cuasi moral. Así, aseveraba que había sido esa universidad posterior a la Reforma de 1918 la que en la historia argentina había actuado cumpliendo "con insobornable dignidad los mandatos de su fe democrática, en defensa de la conciencia republicana amenazada". Claramente se refería al golpe de Estado de 1930 y al de 1943, episodio este último que abriría la puerta al peronismo, asemejado por Romero a un nacionalismo filofascista:

"Dos veces ha triunfado de las fuerzas oscuras que quisieron aniquilarla demoliendo sucesivamente su espíritu y su cuerpo. Triunfó una vez, cuando se lanzaron sobre ella los solapados enemigos de la libertad de pensamiento, pretendiendo restaurar en sus claustros la vigencia de una doctrina superada hace cinco siglos, mezclada, ciertamente, con las modernas y nefastas ideologías totalitarias". (1945:368)

En su pensamiento universitario, Romero imaginaba a la universidad como un espacio virtuoso en el que un "espíritu republicano y democrático velaba vigilante" la vida pública del país, reaccionando contra todo intento "regresivo" al demostrar acabadamente su "su repudio a los que querían escolastilizarla y nazificarla" (1945: 368). Por lo tanto, caracterizaba a la Reforma universitaria como un hecho a todas luces transformador, animado por un "clamor democrático", "aspiración que galvanizó en compacta masa a todos sus miembros: rectores, profesores y estudiantes". Seguidamente, expresaba que de esa universidad reformada solo se habían abierto los numerosos caminos de sus reivindicaciones.

Por ello, es notable percibir el concepto, el perfil ideal de la universidad que Romero señalaba para el período posterior a 1955. Así, en coincidencia con otros actores universitarios del mismo contexto, pensaba que la principal tarea a afrontar y profundizar era la de sellar, para su perduración, el efectivo cumplimiento de los postulados reformistas. Y al asumir el Rectorado de la Universidad de Buenos Aires en calidad de interventor nacional, señaló que la universidad no era "lugar apropiado para los ánimos indolentes ni para los espíritus superficiales" sino que, por el contrario: 
"Conducida democráticamente y por el esfuerzo mancomunado de profesores, egresados y estudiantes, la universidad puede llegar a ser ese vigoroso centro de irradiación que siempre hemos anhelado, en el que se elabore la peculiaridad de nuestra cultura - sin triviales deformaciones nacionalistas- y en el que se preparen despaciosamente las soluciones que el país aguarda para sus problemas fundamentales". (1955: 373)

En la cita que precede asoma enunciado en vínculo entre la universidad y el país, en la medida en que se espera que en esta se elaboren los medios necesarios para alcanzar mejoras colectivas. Romero confiaba en que el trabajo mancomunado y "austero" "por propia determinación y sin necesidad de coacciones externas" posibilitaría una solidaridad tal entre las distintas generaciones que habitaban la sociedad capaz de avanzar hacia el progreso. Asimismo, consideraba a las universidades como un "patrimonio común” (1956a:376), una institución que debía tornarse cada vez más renovada y socialmente eficaz, así indicaba:

"si uno de sus objetivos fundamentales debe ser alcanzar el más alto nivel científico, otro no menos importante debe ser dotarla de la sensibilidad suficiente como para que sirva al desarrollo social del país forrando minorías que no persigan privilegios y que estén animadas por la convicción de sus deberes frente a la sociedad". (1956a: 376)

En 1956, momento crucial de una etapa autorrepresentada por sus principales protagonistas como una verdadera refundación de la cultura y la vida universitaria en la Argentina, Romero reelaboraba la memoria y la tradición política perfilada en torno a la Reforma universitaria desde 1918 en pos de la exhibición de una determinada imagen negativa de la experiencia inmediatamente anterior, aquella en la que el peronismo virtualmente había impregnado a la universidad de un cariz nacionalista, católico y abiertamente antirreformista. En ese sentido, el historiador, por entonces rector de la Universidad de Buenos Aires, afirmaba su punto de vista del antes y del después:

"La universidad nueva fue el objetivo final de la Reforma desencadenada por las juventudes de 1918, y sigue siendo el objetivo final de cuantos aman la libertad y la cultura, jóvenes todos ellos por la juventud del espíritu. Comenzó su camino la universidad nueva entre escollos y vendavales, y a poco de iniciado, lo envolvieron - tras la revolución oligárquica de 1930- las auras maléficas del fascismo que comenzaba a viciar la vida nacional. El camino quedó sumido en aquella niebla enceguecedora, y la meta comenzó a desdibujarse porque los viandantes que recorrían la ruta debieron detenerse a cada paso ante el obstáculo imprevisto. La universidad nueva se tornó una esperanza cada vez más lejana a medida que se apretaban las esposas en las muñecas y las mordazas en los labios. Y parecía razonable ilusión aspirar cada día tan solo a la universidad de la víspera, mejor sin duda que la que se anunciaba para cada uno de los días que se sucedían en la precipitada pendiente que conducía desde la reacción oligárquica hacia el fascismo". (1956b: 377)

Abiertamente, allí se representaba a la universidad peronista como "sombra de sí misma" y seguidamente se certificaba que el "espíritu reformista" había subsistido latente e insobornable en los muchos que habían alzado su voz, los muchos que habían elevado su brazo, y "muchos que levantaron finalmente el arma decisiva" para vencer al peronismo. Con todo, la justificación de la autodenominada "Revolución libertadora" se hacía efectiva al indicar:

"la universidad vibraba en sus juventudes incorruptibles, y resurgió encarnada en ellas tras las jornadas de septiembre, cuando asumieron la custodia de los hogares universitarios. Viva la encontramos cuando creíamos que estaba muerta, porque había vivido en la eterna juventud del espíritu. Y viva existe todavía, viva y anhelante de renovación, para retomar aquel camino en el que se detuviera a poco de comenzar su marcha, cohibida por el enrarecimiento de la atmósfera espiritual del país". (1956b: 377)

La extensión universitaria bajo el prisma de José Luis Romero Hacia 1958, José Luis Romero afirmaba que había llegado la hora de que la universidad trascendiera su tarea puramente académica, asumiendo de este modo una labor de alto tenor educativo y transformador: una misión que pareciera, según señalaba, haber sido trazada específicamente para aquella. Se trataba de la llamada "extensión universitaria", una posibilidad de acción que hacía 40 o 50 años era, según el intelectual, insospechada; razón que demandaba su trascendencia más allá de los claustros y, asimismo, un contacto cercano con la sociedad (1958:393). De este modo, preocupado por una puesta a punto del quehacer universitario, Romero aportaba algunos conceptos sustantivos a su idea extensionista, reflexión que, como ya se puede percibir, no se avecinaba a las concepciones más evidentemente radicales que no tardarían de hacer su ingreso en el repertorio común del examen del problema universitario latinoamericano: piénsese en las proposiciones de, por ejemplo, los brasileros Paulo Freire (19211997) y Darcy Ribeiro (1922-1997).

En ese sentido, la extensión universitaria era propuesta por José Luis Romero como la acción, muchas veces desestimada, que conllevaría a un "nuevo estilo de vida" al interior de las casas de estudios superiores, un talante que tendría un sentido "más amplio y abierto que el tradicional", asentado en la pauta de autoconciencia adquirida por parte de la universidad iberoamericana (1958:394). El intelectual y principalísimo actor universitario llegaba a formular a la extensión como una "modesta organización" que resultaba en experiencias a menudo 


\section{6 \\ la extensión universitaria tendría un sentido "más amplio y abierto que el tradicional", asentado en la pauta de autoconciencia adquirida por parte de la universidad iberoamericana}

subvaloradas. En efecto, Romero buscaba dejar explicitado que debía plasmarse un convencimiento acerca del real valor que portaban e implicaban las actividades de extensión y los mayores réditos que estas podrían prodigar a una tarea política mayor que sería la de "integrar la comunidad nacional". De este modo les hablaba a los extensionistas de finales de la década del ' 50 :

"Querría que (...) quedara grabado en el espíritu de todos los que trabajan en esta actividad, el convencimiento de que no están haciendo nada superfluo y que están trabajando en una tarea más importante de lo que a primera vista parece. Acaso resida en ustedes la posibilidad más fértil de renovación de la universidad argentina". (1958: 394)

\section{Seguidamente aconsejaba:}

"Guardémonos de desdeñar la actividad académica, pero no debemos creer tanto en ella como para suponer que debe privarnos de enfrentarnos con las formas inmediatas de la realidad. Son dos maneras de actuar de la universidad: una es tradicional y goza de respeto; la otra es muy joven y parece una aventura intrascendente o un pasatiempo secundario. Yo quiero contribuir a que cada uno de ustedes vuelva convencido de que trabaja en una actividad que merece el más alto respeto, que está movida por altísimos fines y que tiene en el desarrollo de la vida y de la cultura argentina un papel decisivo". (1958: 394)

Las citas que anteceden son muy valiosas porque permiten leer, a casi 60 años de la enunciación de sus mensajes, al menos tres puntos de apoyo en la construcción de sus sentidos. Primero, José Luis Romero dejaba entrever la imagen ya soslayada que la extensión universitaria poseía en la representación de la mayoría los universitarios hacia 1958, es decir, la plenitud de una idea que aun en la actualidad se renueva y desliza el carácter de una menor jerarquía académica, a diferencia de la investigación y de la docencia. En efecto y como se lee, a Romero le interesaba o le parecía imprescindible subrayar el valor de la extensión cuando tal vez a menudo se la considerara en el cotidiano de la universidad como una actividad "menor", "aventura intrascendente" o "pasatiempo secundario". Segundo, el intelectual progresista proponía a la extensión como una labor pivote para el arribo a la tan anhelada "renovación" de la universidad argentina: esto permite concretar una complejización a la tan resonada renovación de los ‘60. Claramente, Romero no solo impulsaba una actualización epistemológica de la universidad sino que punteaba un programa de transformaciones orientadas a intensificar el vínculo entre universidad y sociedad. Tercero, en la fuente se habla de la presencia de "dos maneras de actuar de la universidad", una relativa a la matriz de corte "tradicional" y, la otra, de tradición "reformista", modelos que habrían de resolverse, según creía Romero, en una reforma necesaria e incesante, habilitando la idea de que no bastaría solo con un episodio reformista sino que, al contrario, implicaría un desafío incesante.

En esa dirección, en el pensamiento universitario de José Luis Romero se comprendía la existencia de una dialéctica

"entre la estructura de la universidad y el impulso perpetuamente renovador del saber que se rehace en ella cada día, porque muere si no acierta a rehacerse, porque no vive sino en su propia y perpetua recreación" (1956b: 379).

Como se puede inferir, el idealismo romeriano suponía el progresismo universitario a partir de la resolución de las contradicciones entre el saber tradicional y un espíritu renovado, una permanente creación de la academia para saldar su propio devenir histórico. Allí, precisamente, y en esa encrucijada, era posible situar para Romero a la Reforma universitaria y a uno de sus postulados más revolucionarios aunque ciertamente postergados: la extensión. En ese sentido, el historiador hablaba de animar la puesta en marcha de una "reforma permanente", un ciclo sin fin de intervenciones vivificadas por el insinuado ideal creativo:

"Yo os digo que no hay una Reforma, sino innumerables y sucesivas reformas; y estoy cierto que ha llegado el momento de una que sea sustancial y profunda. Pero fijémonos cómo hemos de hacerla, porque si ha de hacerse en virtud del espíritu, es imprescindible que sea del espíritu crítico y libre, y no del espíritu dogmático y fundado en el principio de autoridad. Si es este último el que predomina, es seguro que toda reforma será estéril y que finalmente la universidad dejará de serlo". (1956b: 379) 


\section{G6}

Romero claramente consideraba a la
extensión como un nuevo estilo de
comportamiento universitario que, en
tiempos de crisis, sirviera para "descubrir
en cada una de las sociedades la
existencia de problemas sociales"

Como consecuencia de la Reforma universitaria, Romero claramente consideraba a la extensión como la posibilidad de una nueva experiencia vital, un nuevo estilo de comportamiento universitario que, en tiempos de crisis, sirviera para "descubrir en cada una de las sociedades la existencia de problemas sociales". Los claustros, que generalmente se hallaban incapacitados para "comunicarse con el mundo social" debían ahora e imperiosamente iniciar "un período de transformaciones que requerían que todos los sectores de la comunidad nacional entraran en estrecho contacto para comenzar un nuevo modo de vida" (1958:390). Por ello, la imagen de extensión que el historiador e intelectual argentino guiaba se alineaba sobre un anaquel sobre todo filosófico, ideal, más que práctico. En efecto, sobre todo la asociaba a la adopción de una "una nueva actitud universitaria", reinvención que aparecía sin más ligada a transformaciones societales globales, aunque sin ingresar al terreno concreto de las prácticas despejadas de la cotidianeidad universitaria en algún territorio y con actores sociopolíticos específicos. Así, José Luis Romero trazaba el puente entre universidad y sociedad mediante el nexo de lo que para él significaba la extensión:

"[una] preocupación por los problemas sociales, suscitada por circunstancias del momento nacional y circunstancias del momento mundial, desencadenadas por un estado de espíritu de la época, que cuajó en la vida universitaria argentina, como también en el ámbito extrauniversitario, por razones que además contribuían en forma vehemente a que no pudiera dejar de contemplarse la peculiaridad del ambiente social argentino. Esto indujo a muchos universitarios a considerar como una obligación de la universidad la de dirigirse hacia él”. (1958: 390)

\section{A modo de cierre}

Resulta un ejercicio interesante rastrear las huellas de las distintas capas de intervenciones intelectuales que, a su tiempo, se han dedicado a definir los horizontes ideales de la universidad argentina y latinoamericana. A lo largo de este trabajo se han expuesto e interpretado algunas de las ideas que un actor cultural argentino, en su debido contexto, formuló en torno a la Reforma universitaria y a la extensión. De este modo, al retomar la lectura de José Luis Romero sobre los mencionados tópicos, se observa que, en su condición de intelectual abiertamente comprometido con la tradición reformista, sumó aportes al imaginario moderno de una universidad dispuesta a ser un lugar de transformación social, según la sensibilidad progresista que habitaba su numen político y cultural. Estas vistas al pasado adquieren singular relevancia en el presente, cuando es preciso reflexionar acerca de los ángulos de sentido que atraviesan a la universidad pública: ese particular y conflictivo constructo político, concreción resultante del proceso de interacción sociohistórica que se erigió para legitimar y o deslegitimar saberes y órdenes sociales en el marco de la sociedad moderna. Desde esta perspectiva, lo público, como cosa "en común", aparece señalado como dimensión ideal de la puesta en valor de los recortes de cultura, aquellos precisados para la construcción de lo colectivo, traspasando a su vez los límites de las identidades individuales para alcanzar una identificación mayor en torno al Estado. Por ello, la mirada historiográfica posibilita recuperar algunas imágenes relevantes de la universidad en una perspectiva temporal, observando a la crisis universitaria como verdadera caja de resonancia, capaz de evidenciar y experimentar, o tal vez primero experimentar y luego denotar, las fricciones por distintos valores y sentidos en oposición, marcos que remiten a la diversidad de ideas que bulleron en distintas coyunturas. La universidad pública se constituye, de este modo, en uno de los espacios privilegiados en los que se entretejen los hilos de la cultura hegemónica y también las ideas alternativas, así como los dilemas que hacen a la propia constitución social y la misma estructuración de poderes en pugna.

Así, a lo largo de las distintas situacionalidades, con frecuencia es posible advertir las marcas de algunos momentos fuertes que han dejado impresiones sustantivas para el futuro que las relee, ejemplo claro es la Reforma universitaria de 1918, leída fragmentariamente en este trabajo a través de sus marcas en el pensamiento de José Luis Romero. La representación de la Reforma, ese poderoso, atractivo y trunco proyecto originalmente destinado a quebrar la universidad de modelo colonial/excluyente y a abrir el espacio para una modernización consecuente y atenta a la democratización política accesible en la Argentina desde 1916, era resuelto por Romero como una reacción contra la inmovilidad y el anacronismo y como proceso imprescindible de renovación y modernización. La visión romeriana de la Reforma universitaria señalaba y saludaba el enfrentamiento de los claustros en contra los intereses 
de las clases dominantes y en contra del sistema institucional establecido. Como ya se expresó, hacia mediados del siglo XX, fundamentalmente en el momento en que luego del golpe de Estado de 1955 se abriera, paradójicamente, el juego democrático al interior de las universidades nacionales, el historiador socialista consideraba a la tradición reformista un necesario mojón en pos del triunfo de una auténtica democracia. Del mismo modo, nutría una imagen de la universidad, una determinada ponderación histórica de esta como resguardo moral de la democracia frente a los distintos momentos de peligro, de extravío o amenaza de la conciencia republicana.

De esta manera, hacia 1958 José Luis Romero consideró había llegado la hora de que la universidad asumiera una misión transformadora, la "extensión universitaria", que se orientaba a un contacto mayor y cercano con la sociedad. Esa fue concebida como la acción, muchas veces desestimada, no valorada cabalmente, que conllevaría a un nuevo estilo de vida comunitario al interior de las universidades, asentado en la pauta de una autoconciencia adquirida a partir de un espíritu creativo que vencía dialécticamente su oposición a las estructuras. Es notable la forma en que Romero buscó dejar explicitado que debía reivindicarse el real precio que portaban e implicaban las actividades de extensión dado que, a partir de ellas y según pretendía, sería factible integrar la comunidad nacional.

En algunos de los textos escogidos para este trabajo se entrevé cómo a Romero le interesó o le pareció imprescindible subrayar el valor de la extensión, cuestión que permite comprender cómo claramente no solo impulsaba una actualización epistemológica de la universidad sino que, a su vez, pulsaba un programa de transformaciones orientadas a intensificar el vínculo entre esta y la sociedad. También, a distancia o a contramano de las perspectivas más actuales y críticas sobre el extensionismo universitario, aquellos enfoques multidimensionales que discuten acerca de la centralidad de la universidad en vínculos con los otros con los que busca/debe dialogar, comunicar o trabajar mancomunadamente, incluso resolviendo actividades específicas que borren las fronteras entre saber ilustrado y a saber comunitario, bajo el prisma romeriano la extensión aparecía con otras tonalidades. El intelectual e historiador argentino la consideraba como la posibilidad de una nueva experiencia vital, un nuevo estilo de comportamiento universitario que, en tiempos de crisis, valiera para descubrir en cada una de las sociedades la existencia de problemas sociales. Por esto mismo, como ya se dijo en este trabajo, la imagen de extensión de Romero se alineaba sobre un cuadro de base abstracta más que práctica, asociada a la adopción de lo que él llamaba "una nueva actitud universitaria", ligada a transformaciones societales globales, aunque sin ingresar al concreto de las experiencias sociopolíticas en el territorio y con actores sociales precisos.

\section{Referencias bibliográficas}

Acha, O. (2005). La trama profunda. Historia y vida en José Luis Romero. Buenos Aires: El Cielo por Asalto.

Buchbinder, P. (2005). Historia de las universidades argentinas. Buenos Aires:

Sudamericana.

_ (2008). ¿Revolución en los claustros? La Reforma Universitaria de 1918

Buenos Aires: Sudamericana.

Finocchiaro, A. (2013). El mito reformista. Buenos Aires: Eudeba.

Halperin Donghi, T. (1980). José Luis Romero y su lugar en la historiografía argentina. En Halperin Donghi, T. (1996). Ensayos de historiografía. Buenos Aires: El Cielo por Asalto.

_ (2005 [2000]). Vida y muerte de la República verdadera (1910-1930). Buenos Aires: Ariel.

Hobsbawm, E. y Ranger, T. (2002 [1983]). La invención de la tradición. Barcelona: Crítica.

Portantiero, J. C. (1978). Estudiantes y política en América Latina. El proceso de la reforma universitaria (1918-1938). México: Siglo XXI Editores.

Romero, J. L. (1978). En ensayo reformista. En: J. L. Romero (1986), Situaciones e ideologías en América Latina. Buenos Aires: Sudamericana.

(1945). Universidad y democracia. En: J. L. Romero (2004), La experiencia argentina y otros ensayos. Buenos Aires: Taurus.

(1955). Asunción del Rectorado de la Universidad de Buenos Aires. En: J. L. Romero (2004), La experiencia argentina y otros ensayos. Buenos Aires: Taurus. _- (1956a). Defensa de la Universidad. En: J. L. Romero (2004), La experiencia argentina y otros ensayos. Buenos Aires: Taurus.

(1956b). La Reforma Universitaria y el futuro de la universidad argentina. En: J. L. Romero (2004), La experiencia argentina y otros ensayos. Buenos Aires: Taurus.

(1958). La Extensión universitaria. En: J. L. Romero (2004), La experiencia argentina y otros ensayos. Buenos Aires: Taurus.

Tünnermann Bernheim, C. (2008). Noventa años de la Reforma Universitaria de Córdoba (1918-2008). Buenos Aires: Clacso. 